\title{
Correction to: The private healthcare market and the sustainability of an innovative community nurses programme based on social entrepreneurship - CoNSENSo project
}

Roberto Ippoliti ${ }^{1 *}$, Greta Falavigna ${ }^{2}$, Floriana Montani ${ }^{1}$ and Silvia Rizzi ${ }^{1}$

\section{Correction}

Following publication of the original article [1], the author reported that their first names and last names were swapped. The original article has been corrected.

The names appeared on the article as follows:

Ippoliti Roberto

Falavigna Greta

Montani Floriana

Rizzi Silvia

They correct names are as follows:

Roberto Ippoliti

Greta Falavigna

Floriana Montani

Silvia Rizzi

\section{Author details}

${ }^{1}$ Direzione Sanità - Regione Piemonte, Torino, Italy. ${ }^{2}$ Istituto di ricerca sulla crescita economica sostenibile (IRCrES) - Consiglio Nazionale delle Ricerche (CNR), Moncalieri, Italy.

Received: 10 September 2018 Accepted: 2 October 2018

Published online: 11 October 2018

\section{Reference}

1. Roberto I, et al. The private healthcare market and the sustainability of an innovative community nurses programme based on social entrepreneurship - CoNSENSo project. BMC Health Serv Res. 2018;18:689. https://doi.org/10. 1186/s12913-018-3513-z.

* Correspondence: roberto.ippoliti@unito.it

${ }^{1}$ Direzione Sanità - Regione Piemonte, Torino, Italy

Full list of author information is available at the end of the article 